\title{
Stablization of ACOs by NatB mediated N- terminal acetylation is required for ethylene homeostasis
}

\author{
Hai-qing Liu, Ya-jie Zou, Xiao-feng Li, Lei Wu and Guang-qin Guo*
}

\begin{abstract}
$\mathrm{N}$-terminal acetylation (NTA) is a highly abundant protein modification catalyzed by N-terminal acetyltransferases (NATs) in eukaryotes. However, the plant NATs and their biological functions have been poorly explored. Here we reveal that loss of function of CKRC3 and NBC-1, the auxiliary subunit (Naa25) and catalytic subunit (Naa20) of Arabidopsis NatB, respectively, led to defects in skotomorphogenesis and triple responses of ethylene. Proteome profiling and WB test revealed that the 1-amincyclopropane-1-carboxylate oxidase (ACO, catalyzing the last step of ethylene biosynthesis pathway) activity was significantly down-regulated in natb mutants, leading to reduced endogenous ethylene content. The defective phenotypes could be fully rescued by application of exogenous ethylene, but less by its precursor ACC. The present results reveal a previously unknown regulation mechanism at the co-translational protein level for ethylene homeostasis, in which the NatB-mediated NTA of ACOs render them an intracellular stability to maintain ethylene homeostasis for normal growth and responses.
\end{abstract}

Keywords: Ethylene homeostasis, ACC oxidase, N-terminal acetylation, NatB

\section{Introduction}

N-terminal acetylation (NTA) is a form of a highly abundant co- or post-translational protein modification in eukaryotes, in which the $\alpha$-amino group of a protein's $\mathrm{N}$ terminal amino acid is acetylated under the catalysis of $\mathrm{N}$-terminal acetyltransferases (NATs) [1, 2]. NATs are classified as NatA-NatH based on substrate specificity and subunit compositions, which consist of at least one catalytic subunit and auxiliary subunit $[3,4]$. The auxiliary subunits can function as a ribosome anchor, providing substrate specificity, and/or interaction with nascent polypeptides [5]. NTA can alter the steric or chemical properties of the modified N-terminus [6] that may affect protein-protein interaction [7], subcellular localization [8], stability or degradation necessary for

\footnotetext{
* Correspondence: gqguo@lzu.edu.cn
Institute of Cell Biology and MOE Key Laboratory of Cell Activities and Stress

* Correspondence: gqguo@lzu.edu.cn
Institute of Cell Biology and MOE Key Laboratory of Cell Activities and Stress Adaptations, School of Life Sciences, Lanzhou University, Lanzhou 730000, China
}

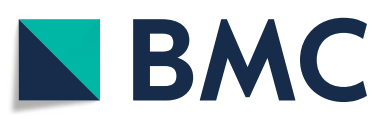

(c) The Author(s). 2021 Open Access This article is licensed under a Creative Commons Attribution 4.0 International License, which permits use, sharing, adaptation, distribution and reproduction in any medium or format, as long as you give appropriate credit to the original author(s) and the source, provide a link to the Creative Commons licence, and indicate if changes were made. The images or other third party material in this article are included in the article's Creative Commons licence, unless indicated otherwise in a credit line to the material. If material is not included in the article's Creative Commons licence and your intended use is not permitted by statutory regulation or exceeds the permitted use, you will need to obtain permission directly from the copyright holder. To view a copy of this licence, visit http://creativecommons.org/licenses/by/4.0/. The Creative Commons Public Domain Dedication waiver (http://creativecommons.org/publicdomain/zero/1.0/) applies to the data made available in this article, unless otherwise stated in a credit line to the data. sponses. Although prevalent, the functional significance of NTA has only recently uncovered in plants, with a limited number of reports on its roles in embyogenesis [9], growth [10], flowering, reproduction [11], stress [12-16] and immunity to pathogens [17].

Ethylene is a classical plant hormone regulating growth and development. Although ethylene biosynthesis has been known as a relatively simple two-step pathway, in which ACO enzymes catalyze the production of ethylene in the last step from ACC, its regulation is still less well understood [18]. For decades it was believed that ACS is the rate-limiting enzyme of this pathway, promoting studies to investigate the regulation of ACS at different levels. However, emerging evidences in recent years reveal that $\mathrm{ACO}$ can also be rate-limiting in ethylene production under certain circumstances [19], implying that the ACOs may be also subjected to a stringent regulation, but its molecular mechanisms is so far 
barely known. The Arabidopsis thaliana ACOs genes have distinct tissue-specific expression patterns. For example, ACO1 (AT2G19590) is highly expressed in embryogenesis [20]. ACO2 (AT1G62380) is mostly expressed in the emerging seedling hypocotyl, where it is involved in the formation of the apical hook [21]. ACO3 (AT1G12010) and ACO5 (AT177330) are mainly expressed in the root [22], and ACO4 (AT1G05010) is mostly expressed in vegetative tissue .

Here, we show that loss of function mutation of NatB led to reduced abundance of three of the five so far known functional $\mathrm{ACO}$ ( $\mathrm{ACO} 2, \mathrm{ACO} 3, \mathrm{ACO} 4)$ to affect ethylene homeostasis for normal growth and responses. Thus the NatB-mediated NTA of ACOs render them an intracellular stability to maintain ethylene homeostasis in vivo.

\section{Results}

\section{NatB is required for normal growth of Arabidopsis}

Previously an Arabidopsis mutant named $c k r c 3$ caused by loss of function mutation of the gene encoding the auxiliary subunit (Naa25/TCU2) of a putative $\mathrm{N}^{\alpha}$-terminal acetyltransferase B (NatB) was isolated as an auxin-deficient mutant in our lab. NatB is one of the eight Nats (NatA - NatH) found so far in eukaryotes, containing a catalytic (Naa20) and an auxiliary subunit (Naa25) to perform its full intracellular functions by cotranslationally catalyzing the NTA of proteins beginning with $\mathrm{MD} / \mathrm{E} / \mathrm{N} / \mathrm{Q}$, as confirmed in our former experiments (paper under-revision elsewhere [23]) and others. Besides auxin-deficiency, $c k r c 3$ and $n b c-1$ displayed pleiotropic developmental defects, including the significantly reduced growth rate (Supplemental Fig. S1), leaf reticulation, early flowering, aborted ovules in short silique (paper under-revision elsewhere).

NatB depletion leads to down-regulation of ACO proteins Since NatB depletion would potentially modulate the abundance of many target proteins, we did global proteomics profiling in seedlings of $c k r c 3, n b c-1$, and double mutant $c k r c 3 n b c-1$ and compared them with those in the wild type (Col-7) seedlings. A total of 6969 proteins were identified. 1.5-fold was taken as the change threshold of differential expression, and $p$-value $<0.05$ was taken as the significance threshold of statistical t-test. In the $c k r c 3 n b c-1 / \mathrm{Col}$ comparison group, 365 protein expressions were up-regulated and 217 protein expressions were down-regulated (Fig. 1A), and differential expressed proteins were discovered to be involved in response to stimulus, post-translation modification and secondary metabolites biosynthesis, transport and catabolism and mainly located in cytoplasm according to GO classifications (Fig. 1B), KEGG enrichments (Fig. 1C) and cluster analysis (Fig. 1D).
Protein annotation enrichment analysis revealed significant down-regulation of protein in a number of biological processes, including immune response, photosynthesis, regulation of proteolysis, regulation of defense response, negative regulation of hydrolase activity, response to host, ion transmembrane transport, hydrogen transport, and ethylene biosynthetic processes, etc. (Fig. 2A). Interestingly, we noted that ethylene biosynthetic processes were significantly down-regulated. In particular, several 1-amincyclopropane-1-carboxylate oxidases (ACOs) were remarkably down-regulated in the enrichment analysis of proteins based on biological processes and molecular function, (Fig. 2B-C, Fig. 3B).

\section{NTA catalyzed by NatB stabilizes ACO2}

In Arabidopsis, three of the five so far known functional ACOs (ACO2, ACO3, ACO4) possess NatB substrate signatures (ME ..., Fig. 3A). Their genes have distinct tissue-specific expression patterns. For example, ACO2 (AT1G62380) is mostly expressed in the emerging seedling hypocotyl, where it is involved in the formation of the apical hook. We also detected relatively high expression levels of $N B C-1$ in cotyledon, root, apical hook, hypocotyls in transgenic proNBC-1::NBC-1-GUS lines (Fig. $3 \mathrm{C}$ ). The NatB-mediated NTA of $\mathrm{ACO} 2 / 4$ has just been reported to occur in Arabidopsis by acetylome analysis, which is significantly decreased in NatB-depleted mutants [10]. In our proteomics profiling data, ACO2/3/4 abundances were reduced 40, 36 and 30\% in $c k r c 3 n b c-1$ compared with those in Col-7, respectively (Fig. 3B), which was also confirmed in WB experiment (Fig. 3E), whereas their transcription was not significantly different (Fig. 3F), indicating that the NTA of ACOs by NatB can stablize the protein post-transcriptionaly. These results are consistent with those of YUC8 in our another investigation [paper under revision elsewhere] as well as two new reports in which NatB-mediated NTA of SNC1 [17] and SIB1 [12] stabilize these two acetylated proteins in plants.

\section{natb mutants were insensitive to ACO inhibitor PZA}

ACOs play an important role in skotomorphogenesis and ethylene response in Arabidopsis, so we examined whether NatB deficiency affects skotomorphogenesis, and finding that $c k r c 3, n b c-1$ and $c k r c 3 n b c-1$ showed defective skotomorphogenesis, including short hypocotyls and roots, and severe apical hook defects (Fig. 5A,Fig. 4). These results indicate that NatB is necessary for normal growth of Arabidopsis in darkness. To further demonstrate the effect of NatB-regulated ACOs on skotomorphogenesis was via ACOs-catalyzed ethylene biosynthesis, we treated etiolated seedlings with ACO inhibitor Pyrazinamide (PZA) [24], the wild type showed longer hypocotyls, roots and defective apical hooks (Fig. 


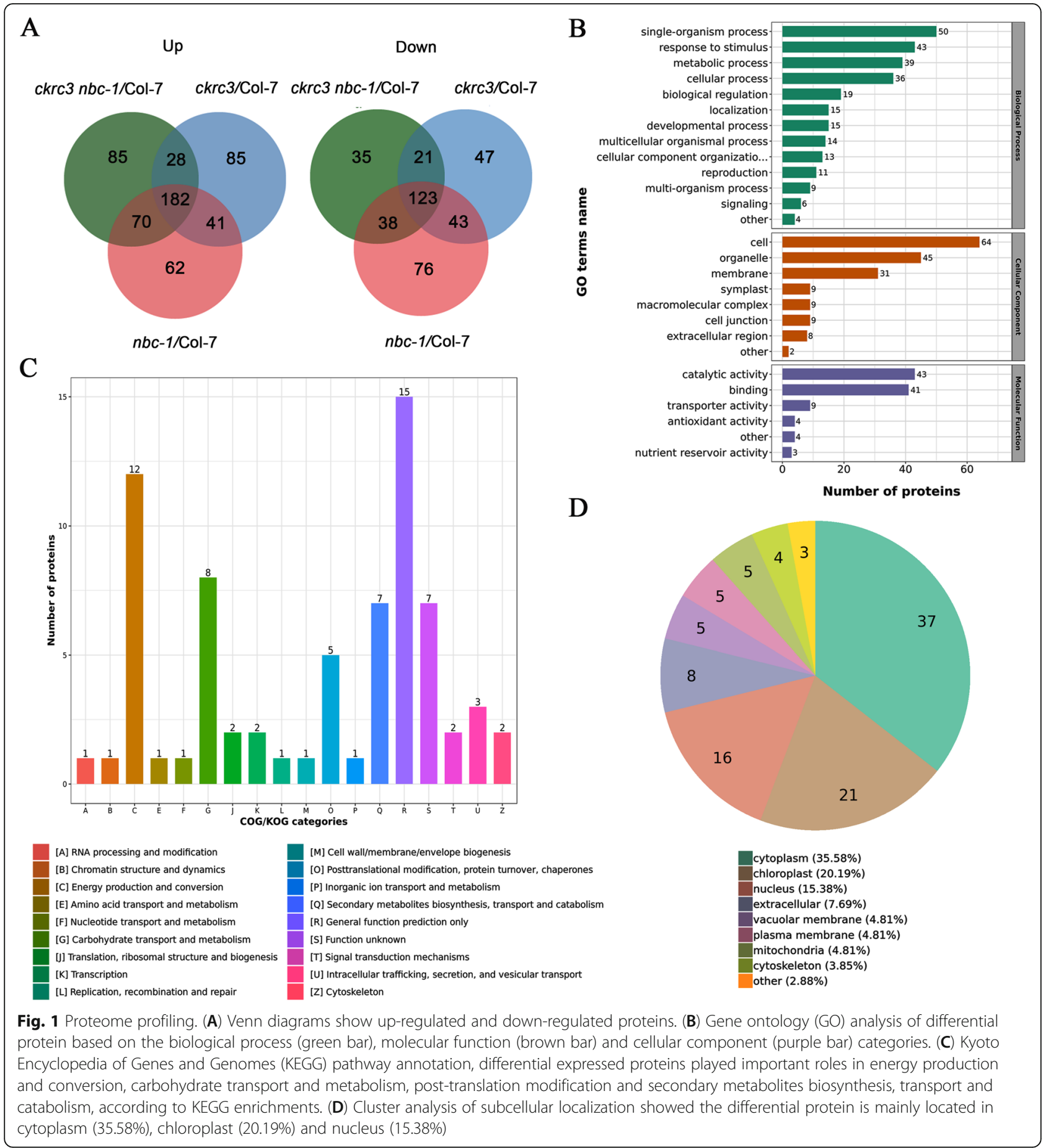

5B-E), suggesting that PZA suppress the basal level of ethylene production, while, treatments of natb mutant with PZA slightly promoted the lengths of their hypocotyls and roots compared with wild type.

\section{NatB regulate ethylene homeostasis}

To directly confirm the role of NatB-mediated NTA of ACOs in ethylene homeostasis, we detected the ethylene content, finding a significant reduction in $c k r c 3 n b c-1$ mutant (Fig. 3D). Ethylene is required for proper skotomotogenesis and the triple-response in the dark, which play protecting roles for seedling before they grow out of soil. The low ethylene level caused by down-regulation of ACOs would led to defects in these processes. To check that, we observed the phenotypes of the 3 mutants in the darkness. As expected, defects in their triple 


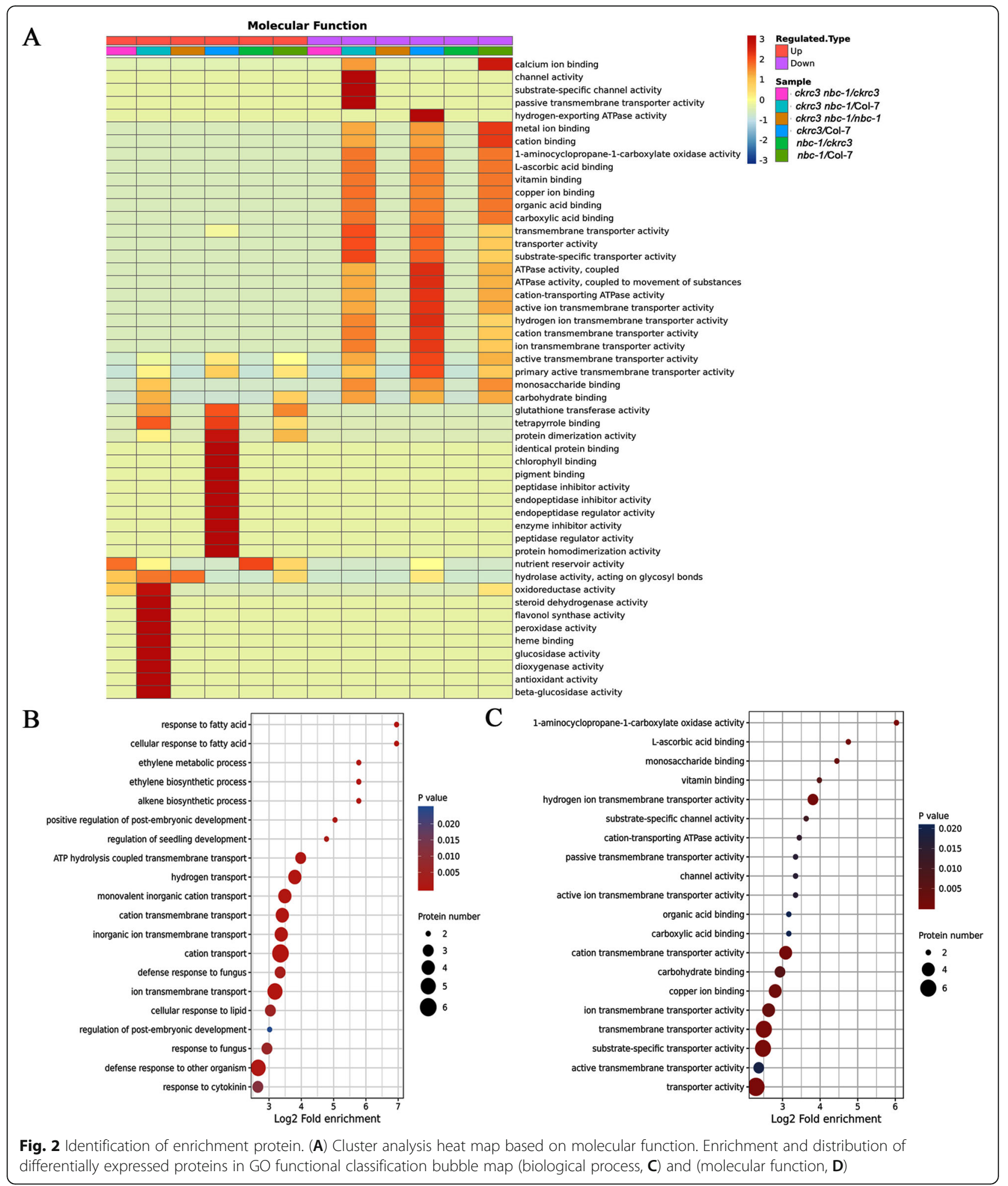

responses (Fig. 6, Supplementary Fig. S2) were observed. Next, we examined the expression of two vital genes responsive to skotomotogenesis, HLS1 and ERF1, detecting their significant down-regulations in $c k r c 3 n b c-1$
(Supplementary Fig. S3), confirming the involvement of NatB in regulating ethylene homeostasis and physiological responses. Notably, these ethylene-related phenotypes could be fully rescued by application of exogenous 

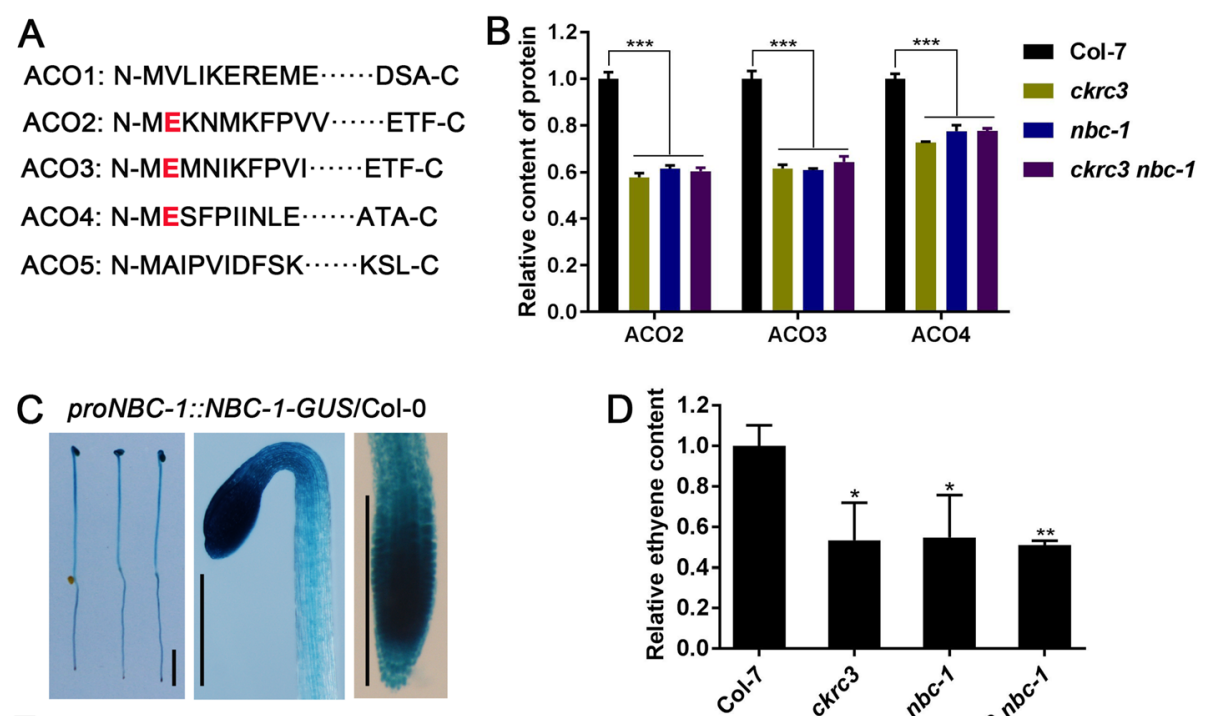

E
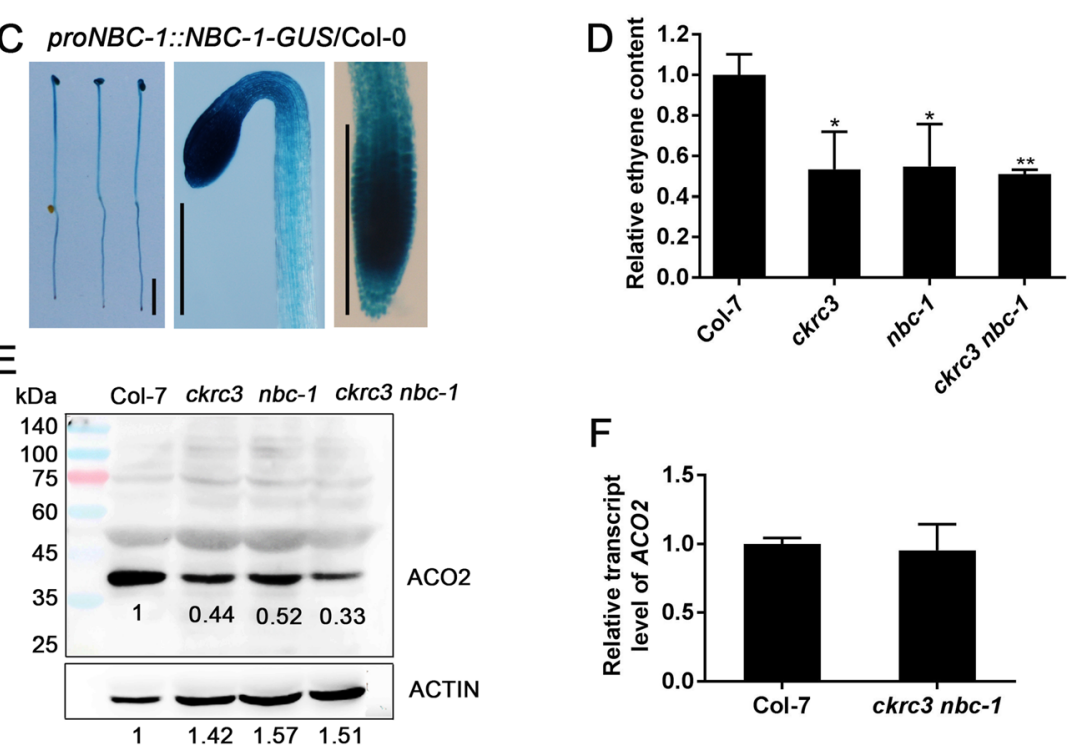

Fig. 3 NTA mediated by NatB stabilizes ACOs. (A) N-terminal peptide of so far 5 known functional ACOs in ethylene biosynthesis in Arabidopsis, specific amino acid of NatB substrate signatures are shown in red colour. (B) Protein levels of ACO2, ACO3 and ACO4 extracted from the whole proteome analysis data. (C) GUS straining of proNBC-1::NBC-1-GUS/Col transgenic seedlings, bar $=2 \mathrm{~mm}$. (D) Quantification results of ethylene contents. (E) ACO2 protein of dark-grown seedlings was detected using ACO2 antibody by WB test, the relative intensity of band in Col-7 was set to 1.0. (F) Transcript levels of ACO2 in dark-grown Col-7 and ckrc3 nbc-1 seedlings by RT-qPCR. "**", "**" and "***" indicate significant differences according to ANOVA followed by Duncan's multiple comparison, $p<0.05, p<0.01$ and $p<0.001$, respectively

ethylene, but less by its precursor ACC (Fig. 6), consistent with the low steady-state levels of $\mathrm{ACO} 2 / 3 / 4$ in NatB mutants (Fig. 3B).

\section{Discussion}

As one of the most common manner of protein modification in eukaryotes, $\mathrm{N}$-terminal acetylation affects the molecular consequence of the substrates in several different ways, including protein stability, protein sorting, subcellular localization, protein folding, and protein interaction $[1,2,6,25]$. NatB is presumed to $\mathrm{N}$-terminal acetylate $15 \%$ of all yeast and $18 \%$ of all human proteins [3]. NatB deficiency will limit both the cellular and physiological function of different protein, and thus impacts a variety of biological processes. For instance, in yeast, the naa20- $\Delta$ and naa25- $\Delta$ deletion mutant strains display abnormal morphology, defects in mitochondrial division, and vacuolar segregation [26], it is also critical for meiosis, as it regulates the assembly of the synaptonemal complex in Caenorhabditis elegans [27]. The silencing of hNAA20 or hNAA25 in human cell lines induces growth arrest [28]. These studies reveal that NTA is involved in cellular processes in various organisms and is extremely important to higher eukaryotes.

In plants, the mutants of NatB subunits, naa20 and naa25, exhibit several developmental defects. Loss of TCU2 function causes pleiotropic developmental defective phenotypes, including vegetative leaves that bend down to the primary vein, clustered flower appearance, shorter floral organ, shorter siliques [11]. Our study showed that NatB functions in normal growth of apical hook, hypocotyl and root of Arabidopsis (Fig. 4, Fig. 5A). Moreover, NatB has positive effect on ehthylene response by promoting ACO stability via NTA (Fig. 3). Xu et al. found that NatB depletion in Arabidopsis caused decreased immunity, which was caused by the destabilization of the plant immune receptor SNC1 [17]. NatB depletion also results in sensitivity to high-salt and osmotic stress [10, 29]. Most recently, NatB-catalyzedNTA was reported to stabilize the stress/immune-related 

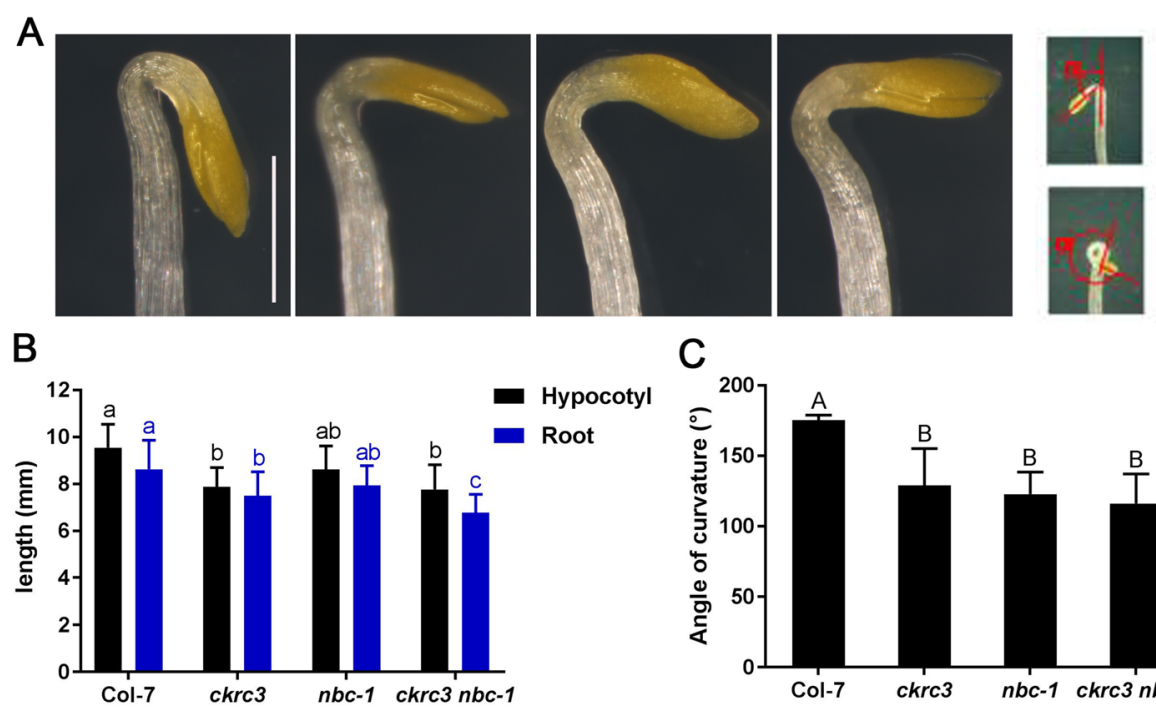

C

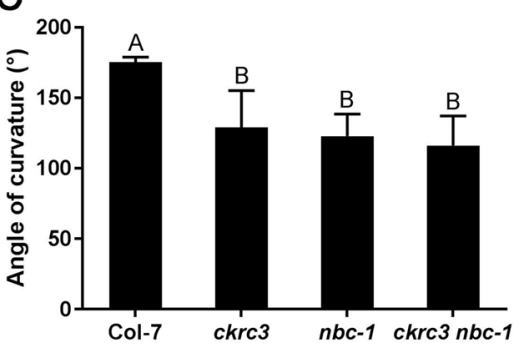

Fig. 4 NatB mutant led to defects of skotomorphogenesis. (A) Phenotypes of apical hook of three DAG etiolated seedlings grown on MS, bar $=2$ $\mathrm{mm}$. (B) Quantification results of hypocotyls and roots length. (C) Quantification results of apical hook, different lowercase and capital letters above the bars indicate significant differences according to ANOVA followed by Duncan's multiple comparison, $p<0.05, p<0.001$, respectively

protein SIB1, enabling its prompt function and the related stress response [12]. These results indicate that in plants, NatB mediated protein NTA also plays vital functions in various processes of growth and responses.

Traditionally, ethylene, as a stress hormone, plays an important role in fruit ripening, tissue and organ aging. While ACO, as a rate-limiting enzyme in ethylene biosynthesis [30, 31], is mainly induced by stress factors, such as flood [32], oxygen deficit [33, 34], osmotic stress [35], and fruit ripening process [36, 37]. An increasing research suggests that ethylene plays an important role in seedling growth by crosstalk with auxin, gibberellin, brassinosteroids and other hormones [38-41], especially in apical hook formation, hypocotyl, and root growth [42-45]. Our study also shows that NTA of ACOs play an indispensable role in apical hook, hypocotyls, and roots growth by increasing their protein stability (Fig. 3); in contrast, their loss of function, with typical insensitivity to ACC but normal response to ethylene (Fig. 6), can cause severe growth defects. Therefore, we propose that the catalytic subunit $\mathrm{NBC}-1$ and the auxiliary subunit CKRC3 function at the ribosome by forming a NatB complex, which actylates ME-startingN-termini directly in cytosol, by this way the NTA modification of ACOs render these proteins more stable to catalyze ethylene biosynthesis and maintain its homeostasis for the normal growth and responses in plants.

\section{Conclusion}

In summary, our results reveal a previously unknown regulation mechanism at the co-translational protein level for ethylene homeostasis in which the NatB- mediated NTA of ACOs render them an intracellular stability to maintain ethylene homeostasis for normal growth and responses. In Arabidopsis, 3 of the 5 ACOs possess NatB substrate signatures (ME) but the others 2 of them not, catalyzing the last step of ethylene biosynthesis pathway in various tissue/organs throughout plant growth and development. As NatB is widely expressed throughout plant development, it would be necessary to investigate roles of NatB-mediated NTA of ACOs in the whole processes of plant growth and development, as well as in the response to stress etc.

\section{Material and methods}

\section{Plant materials}

The mutant $c k r c 3$ in the Col-7 background was isolated in our lab previous, and the mutant library was purchased from The European Arabidopsis Stock Centre, uNASC; http://arabidopsis.info/ (NASC ID: N31400). $n b c-1$ in the Col-0 background, from NASC, and the double mutant $c k r c 3 n b c-1$ were obtained by crossing in our lab .

\section{Growth conditions and phenotype characterization}

Seeds were sterilized with $0.1 \% \mathrm{HgCl}_{2}$, thoroughly washed with $\mathrm{d}_{2} \mathrm{H}_{2} \mathrm{O}$ three times and placed on Murashige Skoog (MS) medium containing 1\% agar and 1\% sucrose. The plates were kept at $4{ }^{\circ} \mathrm{C}$ for 2 days in darkness, then transferred to white light for $8 \mathrm{~h}$ at $22^{\circ} \mathrm{C}$ to stimulate germination, and subsequently to darkness at $20^{\circ} \mathrm{C}$ for 3 days. For chemical treatment, 1aminocyclopropanecarboxylic acid (ACC) and Pyrazinamide (PZA) was supplied to the MS medium for 


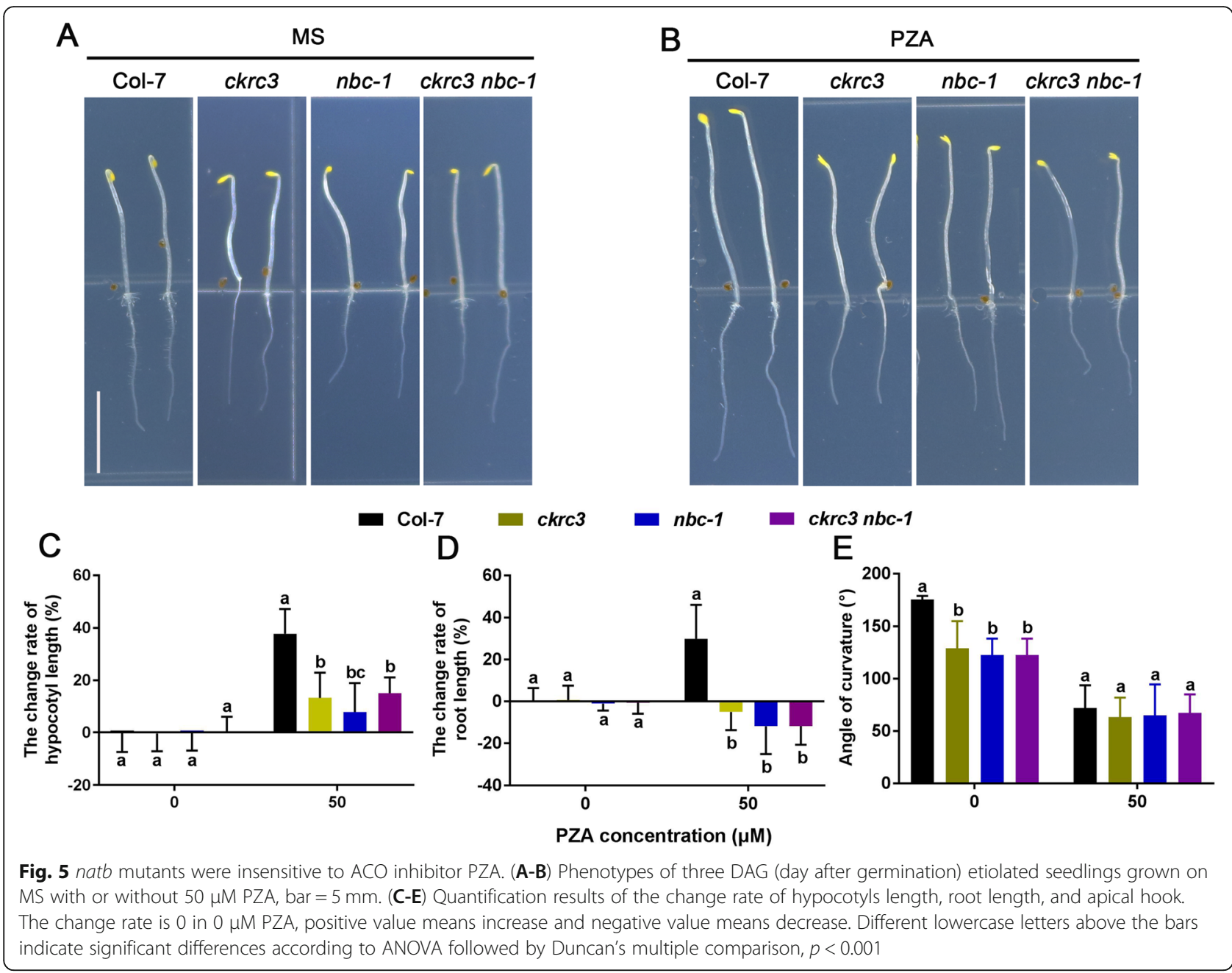

phenotypic analysis. For ethylene treatment, Sterilized seeds were sown in MS medium in $10 \mathrm{~cm} \times 10 \mathrm{~cm}$ plates containing ethylene gas .

\section{RNA extraction and quantitative real-time PCR}

RNA was isolated using Trizol (Invitrogen, http://www. invitro-gen.com/) and reverse-transcribed using a reverse transcription kit (Takara, http://www.takara-bio. com/). Quantitative RT-PCR was performed in Applied Biosystems real-time PCR equipment by using the TB green chemistry (Takara). ACTIN8 was used as an internal control. Quantitative PCR analysis was performed with three different replicates for each biological sample. Three biological replicates were performed in each experiment.

\section{SDS-PAGE and Western blot}

Protein samples were separated by SDS-PAGE and then were transferred to a nitrocellulose blotting membrane. After blocking with $5 \%$ bovine serum albumin, the film was incubated with primary antibody over night at $4{ }^{\circ} \mathrm{C}$, then washed three times with TBST for $10 \mathrm{~min}$ and incubated with secondary antibody for $1 \mathrm{~h}$ at room temperature. After washing four times with TBST for $10 \mathrm{~min}$, the film was illuminated using a luminous imaging system.

\section{Generation of ACO2 antibody}

The purified synthetic peptide ATSLVEKDSEYPS of ACO2 protein was used as the antigen to immunize rabbits for antibody production, performed by Shanghai aibo Biotechnology Co., LTD, China (https://ablebio. company.lookchem.cn/).

\section{Proteomics profiling}

The Arabidopsis seedling were grown on MS medium at $22{ }^{\circ} \mathrm{C}$ with a $16 / 8 \mathrm{~h}$ light/dark cycle for 10 day, About $0.5 \mathrm{~g}$ (3 independent biological replication) seedlings were extracted plant total protein with lysis buffer $(8 \mathrm{M}$ urea, 1\% Triton-100, $10 \mathrm{mM}$ dithiothreitol, and 1\% Protease Inhibitor Cocktail). The protein was digested by trypsin at 1:50 trypsin-to-protein mass ratio. The tryptic 


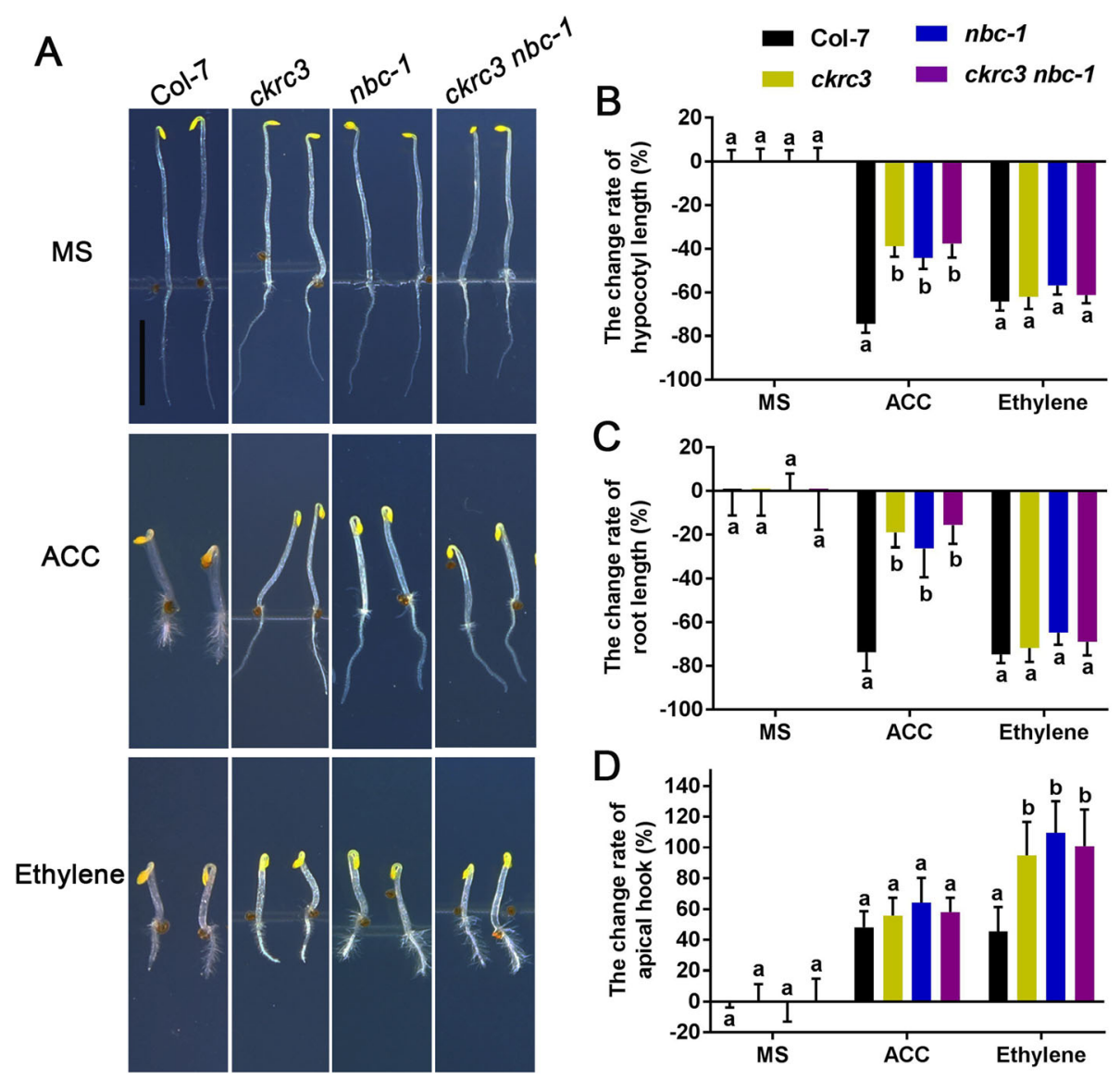

Fig. 6 natb mutants could be fully rescued by application of exogenous ethylene, but less by its precursor ACC. (A) Phenotypes of three DAG etiolated seedlings grown on MS with or without $10 \mu \mathrm{M}$ ACC / $15 \mathrm{ppm}$ ethylene treatments, bar $=5 \mathrm{~mm}$. (B-D) Quantification results of change rate of hypocotyls, root and apical hook. The change rate is 0 in MS, positive value means increase and negative value means decrease. Different lowercase letters above the bars indicate significant differences according to ANOVA followed by Duncan's multiple comparison, $p<0.001$

peptides were desalted with Strata X C18 (Phenomenex) and TMT labeled. The tryptic peptides were fractionated into fractions by high $\mathrm{pH}$ reverse-phase HPLC using Thermo Betasil C18 column ( $5 \mu \mathrm{m}$ particles, $10 \mathrm{~mm}$ ID, $250 \mathrm{~mm}$ length). Then Liquid chromatography (EASYnLC 1000 UPLC system)-mass spectrometry (Q ExactiveTM Plus Thermo) analysis. The resulting MS/MS data were processed using Maxquant search engine (v.1.5.2.8). The whole proteomics test was completed by Hangzhou Jingjie Biology Co., LTD, China (http://www. ptm-biolab.com.cn/).

\section{Expression assay of the NBC-1 gene}

A 3924-bp segment including the promoter and fulllength genomic DNA of NBC-1 were amplified from Col-0 and cloned into pBI101 vector for generating $p N B C-1:: N B C-1-G U S / C o l-0$ transgenic lines. For GUS staining, 3-day-old seedling grown on MS medium in darkness were incubated in $1 \mathrm{mM} \mathrm{X}$-gluc at $37^{\circ} \mathrm{C}$, the GUS staining were observed by using stereomicroscope.

\section{Ethylene quantification}

$100 \mathrm{mg}$ seedlings of Arabidopsis grow 3 days in darkness were put into $5 \mathrm{ml}$ chromatograph (GC) vials (Agilent) with $2 \mathrm{ml} \mathrm{MS}$ medium for $2 \mathrm{~d}$ in darkness. $0.5 \mathrm{ml}$ of the headspace was taken from the vials, and was injected into an gas chromatograph equipment (GC-7820A). Chromatographic column: $\mathrm{AT} \cdot \mathrm{Al}_{2} \mathrm{O}_{3} / \mathrm{S}$; Carrier gas: $\mathrm{N}_{2}$; Gas pressure: $18.33 \mathrm{Kpa}$; Splitless; Gasification chamber temperature: $200{ }^{\circ} \mathrm{C}$.

\section{Statistical analysis}

Data was expressed as mean \pm SD. Statistical analysis were performed with analysis of variance (ANOVA) test to compare differences between more than two groups or treatments.

\section{Supplementary Information}

The online version contains supplementary material available at https://doi. org/10.1186/s12870-021-03090-7.

Additional file 1. 


\section{Additional file 2 .}

\section{Acknowledgments}

The authors thank the support provided by the Experimental Center of the School of Life Sciences, Lanzhou University. Thank for Prof Rujin Chen provided ethylene and gas chromatograph equipment.

\section{Authors' contributions}

GQG directed the experiments; HQL performed the major experiments and wrote the manuscript; YJZ performed tissue localization; HQL, XFL, LW, GQG carried out the statistical analysis. The final revision was accomplished by GQG; All authors contributed to revised manuscript and approved the submitted version.

\section{Funding}

This research was supported by grants from the National Natural Science Foundation of China (grant numbers 3167080163 \& No. 32070721): Open Project of NMPA Key Laboratory for Quality Control of TCM (NMPA Key Laboratory for Quality Control of TCM, Grant No. 2020GSMPA-KL02).

\section{Availability of data and materials}

All the data supporting the results of this article are included within the paper and its supplementary file as figures or tables.

\section{Declarations}

Ethics approval and consent to participate Not applicable.

\section{Consent for publication}

Not applicable.

\section{Competing interests}

The authors declare no competing interests.

Received: 8 March 2021 Accepted: 17 May 2021 Published online: 03 July 2021

\section{References}

1. Aksnes H, Drazic A, Marie M, Arnesen T. First things first: vital protein Marks by N-terminal acetyltransferases. Trends Biochem Sci. 2016;41(9):746-60. https://doi.org/10.1016/j.tibs.2016.07.005

2. Aksnes H, Ree R, Arnesen T. Co-translational, post-translational, and noncatalytic roles of N-terminal acetyltransferases. Mol Cell. 2019;73(6):1097-114. https://doi.org/10.1016/j.molcel.2019.02.007.

3. Starheim KK, Gevaert K, Arnesen T. Protein N-terminal acetyltransferases: when the start matters. Trends Biochem Sci. 2012;37(4):152-61. https://doi. org/10.1016/j.tibs.2012.02.003

4. Linster E, Wirtz M. N-terminal acetylation: an essential protein modification emerges as an important regulator of stress responses. J Exp Bot. 2018; 69(19):4555-68. https://doi.org/10.1093/jxb/ery241.

5. Ree R, Varland $S$, Arnesen T. Spotlight on protein N-terminal acetylation. Exp Mol Med. 2018;50(7):1-13. https://doi.org/10.1038/s12276-018-0116-z.

6. Aksnes $\mathrm{H}$, Hole K, Arnesen T. Molecular, cellular, and physiological significance of N-terminal acetylation. Int Rev Cell Mol Biol. 2015:316:267305. https://doi.org/10.1016/bs.ircmb.2015.01.001

7. Scott DC, Monda JK, Bennett EJ, Harper JW, Schulman BA. N-terminal acetylation acts as an avidity enhancer within an interconnected multiprotein complex. Science. 2011;334(6056):674-8. https://doi.org/10.112 6/science.1209307

8. Aksnes H, Osberg C, Arnesen T. N-terminal acetylation by NatC is not a general determinant for substrate subcellular localization in Saccharomyces cerevisiae. PLoS One. 2013;8(4):e61012. https://doi.org/10.1371/journal.pone. 0061012.

9. Feng J, Li R, Yu J, Ma S, Wu C, Li Y, et al. Protein N-terminal acetylation is required for embryogenesis in Arabidopsis. J Exp Bot. 2016;67(15):4779-89. https://doi.org/10.1093/jxb/erw257.

10. Huber M, Bienvenut W, Linster E, Stephan I, Armbruster L, Sticht C, et al. $\mathrm{NatB}$-mediated $\mathrm{N}$-terminal acetylation affects growth and biotic stress responses. Plant Physiol. 2020;182(2):792-806. https://doi.org/10.1104/pp.19. 00792.

11. Ferrandez-Ayela A, Micol-Ponce R, Sanchez-Garcia AB, Alonso-Peral MM, Micol JL, Ponce MR. Mutation of an Arabidopsis NatB N-alpha-terminal acetylation complex component causes pleiotropic developmental defects. PLoS One. 2013;8(11):e80697. https://doi.org/10.1371/journal.pone.0080697.

12. Li Z, Dogra V, Lee KP, Li R, Li M, Li M, et al. N-terminal acetylation stabilizes SIGMA FACTOR BINDING PROTEIN1 involved in salicylic acid-primed cell death. Plant Physiol. 2020;183(1):358-70. https://doi.org/10.1104/pp.19.0141 7.

13. Armbruster L, Linster E, Boyer JB, Brunje A, Eirich J, Stephan I, et al. NAA50 is an enzymatically active $N$ (alpha)-acetyltransferase that is crucial for development and regulation of stress responses. Plant Physiol. 2020;183(4): 1502-16. https://doi.org/10.1104/pp.20.00222.

14. Feng J, Hu J, Li Y, Li R, Yu H, Ma L. The N-terminal acetyltransferase Naa50 regulates Arabidopsis growth and osmotic stress response. Plant \& cell physiology. 2020;61(9):1565-75. https://doi.org/10.1093/pcp/pcaa081.

15. Linster E, Layer D, Bienvenut W, Dinh TV, Weyer FA, Leemhuis W, et al. The Arabidopsis N (alpha) -acetyltransferase NAA60 locates to the plasma membrane and is vital for the high salt stress response. New Phytol. 2020; 228(2):554-69. https://doi.org/10.1111/nph.16747.

16. Linster E, Stephan I, Bienvenut WV, Maple-Grodem J, Myklebust LM, Huber $\mathrm{M}$, et al. Downregulation of $\mathrm{N}$-terminal acetylation triggers ABA-mediated drought responses in Arabidopsis. Nat Commun. 2015;6(1):7640. https://doi. org/10.1038/ncomms8640.

17. Xu F, Huang Y, Li L, Gannon P, Linster E, Huber M, et al. Two N-terminal acetyltransferases antagonistically regulate the stability of a nod-like receptor in Arabidopsis. Plant Cell. 2015;27(5):1547-62. https://doi.org/10.11 05/tpc.15.00173

18. Pattyn J, Vaughan-Hirsch J, Van de Poel B. The regulation of ethylene biosynthesis: a complex multilevel control circuitry. New Phytol. 2021;229: 770-782. https://doi.org/10.1111/nph.16873.

19. Houben M, Van de Poel B. 1-Aminocyclopropane-1-carboxylic acid oxidase (ACO): the enzyme that makes the plant hormone ethylene. Front Plant Sci. 2019;10:695. https://doi.org/10.3389/fpls.2019.00695.

20. Park CH, Roh J, Youn JH, Son SH, Park JH, Kim SY, et al. Arabidopsis ACC oxidase 1 coordinated by multiple signals mediates ethylene biosynthesis and is involved in root development. Mol Cells. 2018:41(10):923-32.

21. Raz V, Ecker JR. Regulation of differential growth in the apical hook of Arabidopsis. Development. 1999;126(16):3661-8. https://doi.org/10.1242/ dev.126.16.3661.

22. Brady SM, Orlando DA, Lee JY, Wang JY, Koch J, Dinneny JR, et al. A highresolution root spatiotemporal map reveals dominant expression patterns. Science. 2007;318(5851):801-6. https://doi.org/10.1126/science.1146265.

23. H. Q Liu, D. W Di, Y. M Guo, J. L Wang, L. Zhang, P. Tian, Q. H Fei, X. F Li, A. J Khaskheli, L. Wu, and G. Q Guo, Significance of NatB-mediated N-terminal acetylation of the auxin biosynthetic enzymes in maintaining auxin homeostasis in Arabidopsis thaliana, Communications biology, under-revision.

24. Sun $X, L i Y$, He W, Ji C, Xia P, Wang Y, et al. Pyrazinamide and derivatives block ethylene biosynthesis by inhibiting ACC oxidase. Nat Commun. 2017; 8(1):15758. https://doi.org/10.1038/ncomms15758.

25. Hwang CS, Shemorry A, Varshavsky A. N-terminal acetylation of cellular proteins creates specific degradation signals. Science. 2010;327(5968):973-7. https://doi.org/10.1126/science.1183147

26. Alves S, Neiri L, Chaves SR, Vieira S, Trindade D, Manon S, et al. N-terminal acetylation modulates Bax targeting to mitochondria. Int J Biochem Cell Biol. 2017;95:35-42.

27. Gao J, Barroso C, Zhang P, Kim HM, Li S, Labrador L, et al. N-terminal acetylation promotes synaptonemal complex assembly in C. elegans. Genes Dev. 2016;30(21):2404-16. https://doi.org/10.1101/gad.277350.116.

28. Starheim KK, Arnesen T, Gromyko D, Ryningen A, Varhaug JE, Lillehaug JR. Identification of the human N (alpha)-acetyltransferase complex B (hNatB): a complex important for cell-cycle progression. Biochem J. 2008;415(2):32531. https://doi.org/10.1042/BJ20080658.

29. Van Damme P, Lasa M, Polevoda B, Gazquez C, Elosegui-Artola A, Kim DS, et al. N-terminal acetylome analyses and functional insights of the $\mathrm{N}$ terminal acetyltransferase NatB. Proc Natl Acad Sci U S A. 2012;109(31): 12449-54. https://doi.org/10.1073/pnas.1210303109.

30. Penrose DM, Glick BR. Enzymes that regulate ethylene levels--1aminocyclopropane-1-carboxylic acid (ACC) deaminase, ACC synthase and ACC oxidase. Indian J Exp Biol. 1997;35(1):1-17. 
31. Moeder W, Barry CS, Tauriainen AA, Betz C, Tuomainen J, Utriainen M, et al. Ethylene synthesis regulated by biphasic induction of 1-

aminocyclopropane-1-carboxylic acid synthase and 1-aminocyclopropane-1carboxylic acid oxidase genes is required for hydrogen peroxide accumulation and cell death in ozone-exposed tomato. Plant Physiol. 2002; 130(4):1918-26. https://doi.org/10.1104/pp.009712.

32. Ramadoss N, Gupta D, Vaidya BN, Joshee N, Basu C. Functional characterization of 1-aminocyclopropane-1-carboxylic acid oxidase gene in Arabidopsis thaliana and its potential in providing flood tolerance. Biochem Biophys Res Commun. 2018;503(1):365-70. https://doi.org/10.1016/j.bbrc.201 8.06.036.

33. Sell $\mathrm{S}$, Hehl R. A fifth member of the tomato 1-aminocyclopropane-1carboxylic acid (ACC) oxidase gene family harbours a leucine zipper and is anaerobically induced. DNA sequence : the journal of DNA sequencing and mapping. 2005;16(1):80-2. https://doi.org/10.1080/10425170500050817.

34. English PJ, Lycett GW, Roberts JA, Jackson MB. Increased 1Aminocyclopropane-1-carboxylic acid oxidase activity in shoots of flooded tomato plants raises ethylene production to physiologically active levels. Plant Physiol. 1995;109(4):1435-40. https://doi.org/10.1104/pp.109.4.1435

35. Jia H, Chen S, Liu D, Liesche J, Shi C, Wang J, et al. Ethylene-induced hydrogen sulfide negatively regulates ethylene biosynthesis by Persulfidation of ACO in tomato under osmotic stress. Front Plant Sci. 2018; 9:1517. https://doi.org/10.3389/fpls.2018.01517.

36. Rombaldi C, Lelievre JM, Latche A, Petitprez M, Bouzayen M, Pech JC. Immunocytolocalization of 1-aminocyclopropane-1-carboxylic acid oxidase in tomato and apple fruit. Planta. 1994;192(4):453-60. https://doi.org/10.1 007/BF00203582

37. Atkinson RG, Gunaseelan $K$, Wang MY, Luo L, Wang T, Norling CL, et al. Dissecting the role of climacteric ethylene in kiwifruit (Actinidia chinensis) ripening using a 1-aminocyclopropane-1-carboxylic acid oxidase knockdown line. J Exp Bot. 2011;62(11):3821-35. https://doi.org/10.1093/jxb/ erro63.

38. De Grauwe L, Vandenbussche F, Tietz O, Palme K, Van Der Straeten D. Auxin, ethylene and brassinosteroids: tripartite control of growth in the Arabidopsis hypocotyl. Plant \& cell physiology. 2005;46(6):827-36. https:// doi.org/10.1093/pcp/pci111.

39. Mazzella MA, Casal JJ, Muschietti JP, Fox AR. Hormonal networks involved in apical hook development in darkness and their response to light. Front Plant Sci. 2014:5:52.

40. Song S, Huang H, Gao H, Wang J, Wu D, Liu X, et al. Interaction between MYC2 and ETHYLENE INSENSITIVE3 modulates antagonism between jasmonate and ethylene signaling in Arabidopsis. Plant Cell. 2014;26(1):26379. https://doi.org/10.1105/tpc.113.120394.

41. Zhang X, Zhu Z, An F, Hao D, Li P, Song J, et al. Jasmonate-activated MYC2 represses ETHYLENE INSENSITIVE3 activity to antagonize ethylene-promoted apical hook formation in Arabidopsis. Plant Cell. 2014;26(3):1105-17. https:// doi.org/10.1105/tpc.113.122002.

42. Miao ZQ, Zhao PX, Mao JL, Yu LH, Yuan Y, Tang H, et al. HOMEOBOX PROTEIN52 mediates the crosstalk between ethylene and auxin signaling during primary root elongation by modulating auxin transport-related gene expression. Plant Cell. 2018;30(11):2761-78. https://doi.org/10.1105/tpc.18. 00584.

43. Stepanova AN, Hoyt JM, Hamilton AA, Alonso JM. A link between ethylene and auxin uncovered by the characterization of two root-specific ethyleneinsensitive mutants in Arabidopsis. Plant Cell. 2005;17(8):2230-42. https:// doi.org/10.1105/tpc.105.033365

44. Vriezen WH, Achard P, Harberd NP, Van Der Straeten D. Ethylene-mediated enhancement of apical hook formation in etiolated Arabidopsis thaliana seedlings is gibberellin dependent. The Plant journal : for cell and molecular biology. 2004;37(4):505-16. https://doi.org/10.1046/j.1365-313X.2003.01975.x.

45. Zadnikova P, Wabnik K, Abuzeineh A, Gallemi M, Van Der Straeten D, Smith RS, et al. A model of differential growth-guided apical hook formation in plants. Plant Cell. 2016;28(10):2464-77. https://doi.org/10.1105/tpc.15.00569.

\section{Publisher's Note}

Springer Nature remains neutral with regard to jurisdictional claims in published maps and institutional affiliations.

\section{Ready to submit your research? Choose BMC and benefit from:}

- fast, convenient online submission

- thorough peer review by experienced researchers in your field

- rapid publication on acceptance

- support for research data, including large and complex data types

- gold Open Access which fosters wider collaboration and increased citations

- maximum visibility for your research: over $100 \mathrm{M}$ website views per year

At BMC, research is always in progress.

Learn more biomedcentral.com/submissions 